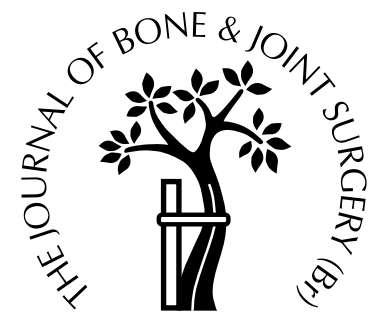

\title{
The treatment of congenital club foot by operation to correct deformity and achieve dynamic muscle balance
}

\author{
Y.-T. Huang, W. Lei, L. Zhao, J. Wang \\ From Xi-Jing Hospital, Xi'an, China
}

$\mathbf{W}$ e operated on 111 patients with 159 congenital club feet with the aim of correcting the deformity and achieving dynamic muscle balance. Clinical and biomechanical assessment was undertaken at least six years after operation when the patient was more than 13 years of age. The mean follow-up was for 11 years 10 months (6 to 36 years).

Good and excellent results were obtained in $91.8 \%$. Patients with normal function of the calf had a better outcome than those with weak calf muscles. The radiological changes were assessed in relation to the clinical outcome. The distribution of pressure under the foot was measured for biomechanical assessment.

Our results support the view that muscle imbalance is an aetiological factor in club foot. Early surgery seems to be preferable. It is suggested that operation should be undertaken as soon as possible after the age of six months, although it may be carried out up to the age of five years. The establishment of dynamic muscle balance appears to be an effective method of maintaining correction. Satisfactory long-term results can be achieved with adequate appearance and function.

J Bone Joint Surg [Br] 1999;81-B:858-62.

Received 4 August 1998; Accepted after revision 26 January 1999

The aim of the treatment of congenital club foot is to obtain a functional, painfree, plantigrade foot which is able to wear a normal shoe. Most surgeons agree that the initial treatment should be non-operative. ${ }^{1-3}$ Early surgery has been advocated for the foot which does not respond to initial conservative treatment or which relapses. ${ }^{1,4-6}$

Y.-T. Huang, MD, Professor of Orthopaedic Surgery

W. Lei, MD, Senior Lecturer

L. Zhao, MD, Associate Professor

J. Wang, MSc, Computer Engineer

PLA Institute of Orthopaedics, Xi-Jing Hospital, Fourth Military Medical

University, Xi' an 710032, People's Republic of China.

Correspondence should be sent to Dr L. Zhao.

(C)1999 British Editorial Society of Bone and Joint Surgery

0301-620X/99/59354\$2.00
Various methods of surgical treatment of club foot have been introduced which depend on their proponents' view of the aetiology and pathoanatomy. ${ }^{4,6-9}$ It has been suggested that muscle imbalance is an aetiological factor. ${ }^{4,10-13}$ The aim of surgery is to correct the deformities of equinus, inversion and adduction and to achieve dynamic muscle balance in order to maintain the correction.

We report the long-term results of the treatment of congenital club foot by an operation which corrects these deformities and achieves dynamic muscle balance.

\section{Patients and Methods}

Between 1957 and 1994, we treated 1088 children aged from three months to 12 years, with 1521 club feet, by an operation to correct the deformity and achieve dynamic muscle balance. To determine the long-term results patients included in this study had to attend for clinical and radiological assessment and be over the age of 13 years at least six years after the operation. Of the 1088 patients, 111 (75 males and 36 females) fulfilled these criteria. The left foot was affected in 26, the right in 37 and the condition was bilateral in 48 . The age at operation ranged from six months to 12 years (Table I). The severity of the deformity was measured before operation using the angle of the longitudinal axis of the foot to the line connecting the medial and lateral malleoli (F-M angle). The smaller the angle, the worse was the deformity. Before operation, 29 feet were classified as mild ( F-M >80), 70 as moderate ( FM 70 to 80$)$ and 60 as severe $(\mathrm{F}-\mathrm{M}<70)$ using this measurement. The muscle power of the peronei was assessed as weak in all the patients. There was reduced strength in tibialis anterior (grade IV) and in tibialis poster-
Table I. Age of the 111 patients with club foot at the time of operation

\begin{tabular}{lcc}
\hline $\begin{array}{l}\text { Age } \\
(\mathbf{y r})\end{array}$ & $\begin{array}{l}\text { Number of } \\
\text { patients }\end{array}$ & $\begin{array}{l}\text { Number of } \\
\text { feet }\end{array}$ \\
\hline 0.5 to 1 & 20 & 33 \\
1 to 3 & 29 & 35 \\
3 to 5 & 32 & 51 \\
5 to 10 & 27 & 36 \\
10 to 12 & 3 & 4 \\
Total & 111 & 159 \\
\hline
\end{tabular}

THE JOURNAL OF BONE AND JOINT SURGERY 
Table II. Surgical procedures undertaken in 159 club feet

\begin{tabular}{lc}
\hline Main procedures & Number of feet \\
\hline Percutaneous tenotomy of tendo Achillis & 22 \\
Lengthening of tendo Achillis & 137 \\
Posterior capsulotomy of the ankle and subtalar joints & 47 \\
Releasing of the posterior tibial neurovascular bundle & 14 \\
$\begin{array}{l}\text { Lengthening of the posterior tibial tendon, flexor } \\
\text { hallucis longus tendon and flexor digiti longus tendon }\end{array}$ & 13 \\
Medial release and wedge resection of the cuboid & 15 \\
\hline
\end{tabular}

ior and the triceps surae (grades III to IV) in 70 feet. These muscles were considered to be normal in 89 feet.

The mean follow-up was for 11 years 10 months ( 6 to 36 years). The mean age at follow-up was 20 years (13 to 40).

Operative technique. The surgical procedures performed to correct deformity are shown in Table II. Rebalancing was achieved by lateral transfer of the tendon of tibialis anterior to the second cuneiform in two feet, to the third cuneiform in 67 , to the medial part of the cuboid in 88 and to the base of the fifth metatarsal in two. The site of reinsertion depended on the severity of the deformity, the power of the tibialis anterior and the peronei and on the position at which the lifting force was judged to achieve the best correction of the deformity during the operation. A long-leg plaster cast was applied with the knee in $90^{\circ}$ of flexion, the ankle in $0^{\circ}$ to $5^{\circ}$ of dorsiflexion and the foot in mild abduction and eversion. The cast was worn for six weeks before the wire used for reinsertion of the transferred tendon was removed and the patient was then allowed to mobilise.

Clinical assessment. The grading system shown in Table III and based on others in the literature ${ }^{9,12,14}$ was used for the assessment of the results. This allocates five points for self-assessment by the patient, 45 points for function, 30 for appearance and 20 for radiological changes. A score of 86 to 100 points was rated as excellent, 71 to 85 as good, 56 to 70 as fair and less than 56 points as poor.

Radiological measurements. In the patients with unilateral club foot anteroposterior (AP) and lateral radiographs were taken using the standardised method of Simons. ${ }^{15}$ Radiographs of the opposite normal foot were used as controls. We used a computer-assisted image-processing and analysing system for the radiological measurements as follows:

1) From the AP view we measured:

a) The talometatarsal (T-M) angle between the axial lines of the talus and the first metatarsal. A negative T-M angle indicated adduction of the forefoot.

b) The calcaneocuboid angle as the angle between the longitudinal axes of the cuboid and the calcaneus.

c) The calcaneometatarsal angle as the angle between the longitudinal axes of the fifth metatarsal and the calcaneus.

d) The length of the first and fifth metatarsal.

2) From the lateral radiograph we measured:
Table III. Criteria for assessing the result of treatment of congenital club foot

\begin{tabular}{|c|c|}
\hline & $\begin{array}{l}\text { Score } \\
\text { (points) }\end{array}$ \\
\hline \multicolumn{2}{|l|}{ Patient } \\
\hline Satisfactory & 5 \\
\hline Less satisfactory & 3 \\
\hline Unsatisfactory & 0 \\
\hline \multicolumn{2}{|l|}{ Foot function } \\
\hline \multicolumn{2}{|l|}{ Painful (foot and ankle) } \\
\hline Nil & 8 \\
\hline Painful at excessive exercise & 6 \\
\hline Painful at normal exercise & 4 \\
\hline Painful at walking & 0 \\
\hline \multicolumn{2}{|l|}{ Gait } \\
\hline Normal & 5 \\
\hline Internal torsion or mild limping & 3 \\
\hline Walking on toes or evident limping & 0 \\
\hline \multicolumn{2}{|l|}{ Movement of ankle } \\
\hline Dorsiflexion $>10^{\circ}$, plantar flexion $>40^{\circ}$ & 8 \\
\hline Dorsiflexion $5^{\circ}$ to $10^{\circ}$, plantar flexion $20^{\circ}$ to $40^{\circ}$ & 6 \\
\hline Dorsiflexion $<5^{\circ}$ or stiffened in neutral position & 4 \\
\hline Stiffened in relapsed position & 0 \\
\hline \multicolumn{2}{|l|}{ Muscle function } \\
\hline \multicolumn{2}{|l|}{ Transferred anterior tibialis } \\
\hline Complete & 8 \\
\hline Partial & 4 \\
\hline Nil & 0 \\
\hline \multicolumn{2}{|l|}{ Triceps surae } \\
\hline Complete & 8 \\
\hline Partial & 4 \\
\hline Nil & 0 \\
\hline \multicolumn{2}{|l|}{ Posterior tibialis } \\
\hline Complete & 8 \\
\hline Partial & 4 \\
\hline Nil & 0 \\
\hline \multicolumn{2}{|l|}{ Appearance of foot } \\
\hline \multicolumn{2}{|l|}{ Development } \\
\hline Well-developed and plantigrade & 8 \\
\hline Poorly-developed and plantigrade & 6 \\
\hline Mild cavus or eversion & 2 \\
\hline Evident equinovarus or/cavus and eversion & 0 \\
\hline \multicolumn{2}{|l|}{ Position of heel } \\
\hline Neutral & 8 \\
\hline Eversion $<5^{\circ}$ & 5 \\
\hline Eversion $>5^{\circ}$ or inversion & 0 \\
\hline \multicolumn{2}{|l|}{ Position of forefoot } \\
\hline Neutral & 8 \\
\hline Inversion or eversion $<5^{\circ}$ & 5 \\
\hline Inversion or eversion $>5^{\circ}$ & 0 \\
\hline \multicolumn{2}{|l|}{ F-M angle } \\
\hline$>80^{\circ}$ & 6 \\
\hline 70 to $80^{\circ}$ & 3 \\
\hline$<70^{\circ}$ & 0 \\
\hline Radiological measurements & \\
\hline TC-AP angle & \\
\hline$\geq 25^{\circ}$ & 5 \\
\hline $10^{\circ}$ to $24^{\circ}$ & 3 \\
\hline$<10^{\circ}$ & 0 \\
\hline TC-L angle & \\
\hline$\geq 20^{\circ}$ & 5 \\
\hline $10^{\circ}$ to $19^{\circ}$ & 3 \\
\hline$<10^{\circ}$ & 0 \\
\hline T-M angle & \\
\hline$\leq 20^{\circ}$ & 5 \\
\hline $21^{\circ}$ to $30^{\circ}$ & 3 \\
\hline$>30^{\circ}$ & 0 \\
\hline Axis of talus, navicular, cuneiform or metatarsus & \\
\hline Normal & 5 \\
\hline Mild change & 3 \\
\hline Severe change & 0 \\
\hline
\end{tabular}


a) The length of the talus and the calcaneus and the size of the talar knot.

b) The shape of the trochlea and the head of the talus. 3) To assess the hindfoot, the talocalcaneal index (TC index) was calculated by measuring the talocalcaneal angle on both the AP (TC-AP) and lateral views (TC-L).

Measurement of foot pressure. We measured the foot pressure in 33 (42 feet) of the 111 patients. There were 20 men and 13 women, with 42 involved feet. The mean age at follow-up was 17 years (13 to 32). The mean height was $155 \mathrm{~cm}$ (142 to 167) and the mean body-weight $45 \mathrm{~kg}$ (41 to $75)$. The mean length of the involved foot was $22 \mathrm{~cm}$ (17 to 25). Dynamic force-plate measurements were made using an optical method. ${ }^{16,17}$ The patients walked on a glass plate, which was covered by a sheet of soft white plastic and attached to a video camera recording apparatus connected to a computer-assisted image-processing system. The static and dynamic images were recorded at 24 frames per second and digitised for data storage. They could be displayed frame by frame or continuously on a television monitor for dynamic studies. The areas of interest for pressure measurement are outlined in Figure 1. The pressure distribution under the foot was measured in relation to the ground-contact time, pressure profile and other biomechanical parameters for each area of interest during the stance phase through a single step. The data from these measurements were processed and analysed using Harvard Graphics V3.0 software (Software Publishing Corporation, USA).

Statistical analysis. The results of treatment were graded according to the points system in Table III. Statistical significance was obtained by the chi-squared test. Other data were evaluated by analysis of variance followed by

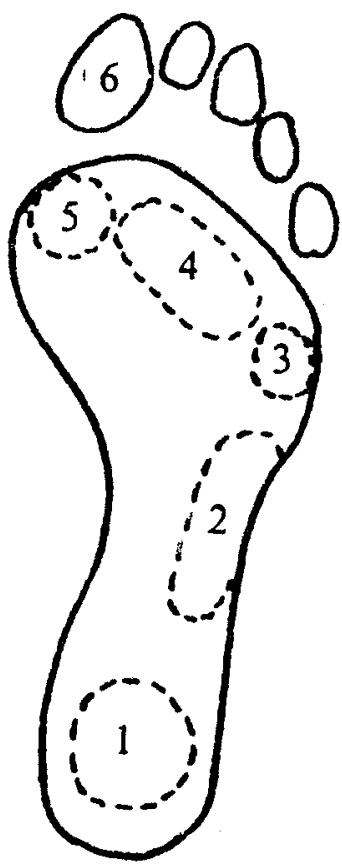

Fig. 1

Diagram showing the selected areas of interest for the pressure measurement under the foot: 1 , heel; 2, lateral part of the sole; 3 , fifth metatarsal head; 4, second, third and fourth metatarsal heads; 5 , first metatarsal head; 6 , hallux.
Student's $t$-test. A p value of less than 0.05 was considered significant.

\section{$\underline{\text { Results }}$}

Clinical outcome. Using the scoring system described in Table III, 87 feet $(54.7 \%)$ were considered excellent, 59 (37.1\%) good, eight $(5 \%)$ fair and five $(3.1 \%)$ poor. Overall, 146 feet $(91.8 \%)$ were rated as excellent or good (Fig. 2).

In the 63 unilateral feet which were considered to have an excellent or good result there were still significant differences in the length, width and height of the foot and in the calf circumference compared with the opposite normal side (Table IV). Good or excellent results were observed in 83 of the 89 feet $(93 \%)$ in which calf function was assessed as normal and in 63 of the 70 feet $(90 \%)$ in which it was weak.

Table IV. Mean measurements $(\mathrm{cm} ; \pm \mathrm{SD})$ of the development of the foot and leg in 63 unilateral club feet compared with control feet

\begin{tabular}{lrrl}
\hline & \multicolumn{1}{c}{ Control } & \multicolumn{1}{c}{ Affected } & p value \\
\hline Foot length & $22.19 \pm 1.69$ & $20.68 \pm 2.08$ & $<0.01$ \\
Foot width & $7.93 \pm 0.82$ & $7.53 \pm 1.04$ & $<0.01$ \\
Foot height & $7.09 \pm 0.84$ & $6.91 \pm 1.03$ & $<0.05$ \\
Shank girth & $29.43 \pm 3.39$ & $27.21 \pm 2.86$ & $<0.01$ \\
\hline
\end{tabular}

Table V. Correlation of the results of treatment with the severity of the deformity

\begin{tabular}{lll}
\hline Deformity & $\begin{array}{l}\text { Number of } \\
\text { feet }\end{array}$ & $\begin{array}{l}\text { Good and excellent } \\
\text { result }(\%)\end{array}$ \\
\hline Mild & 29 & 98.2 \\
Moderate & 70 & 92.9 \\
Severe & 60 & 88.3 \\
\hline
\end{tabular}

Feet with mild or moderate deformity had a better outcome than those with severe deformity (Table V). Patients whose operation was performed under the age of five years had better results than those over five years.

Biomechanical measurements. Of the 42 feet which had dynamic force-plate measurements 35 were rated good or excellent and seven fair or poor by our scoring system. Data from the involved foot were compared with the opposite normal foot in unilateral cases and with a control group matched for age, gender, height, weight and length of the foot in bilateral cases.

Distribution of dynamic pressure under the foot. The distribution of dynamic pressure under the foot was almost normal in the 35 feet with good or excellent results, whereas it was significantly different $(p<0.05)$ in the seven feet with fair or poor results. In these feet the time of full-foot ground contact was shorter and the time of heeloff longer than for the control foot.

Peak pressure under the foot. Static peak pressure for all the selected areas under the affected foot was almost 


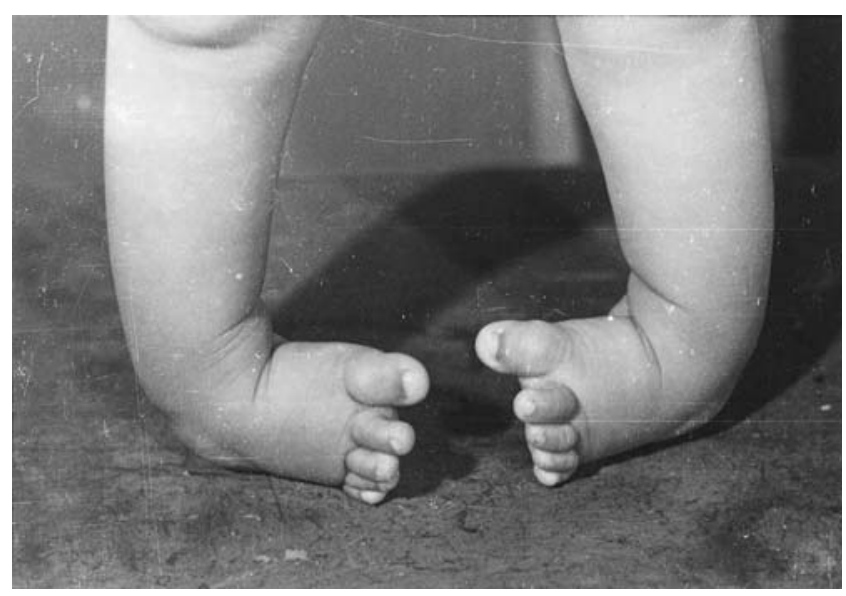

Fig. 2a

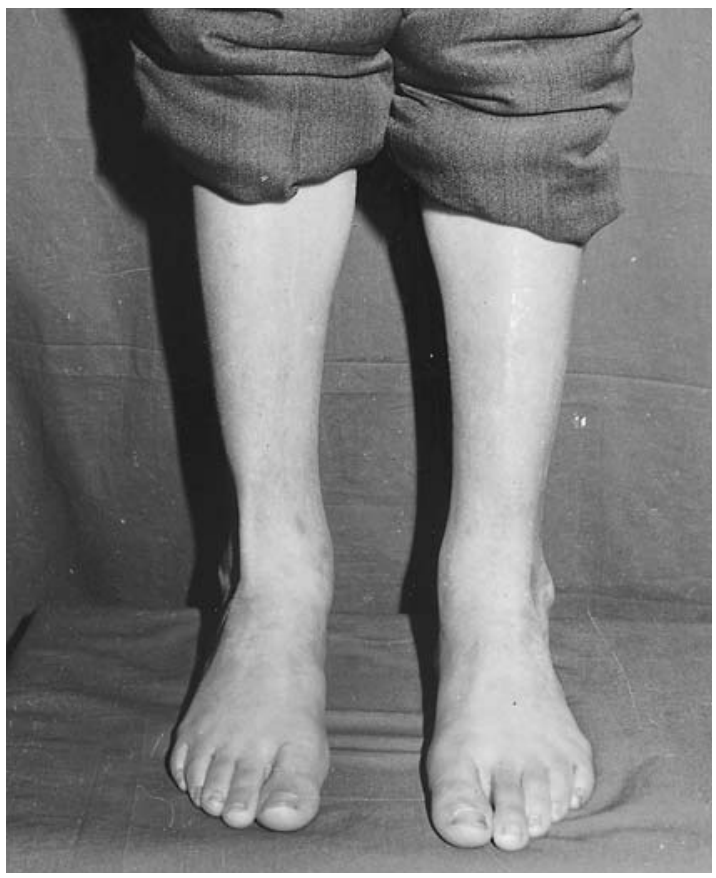

Fig. 2c

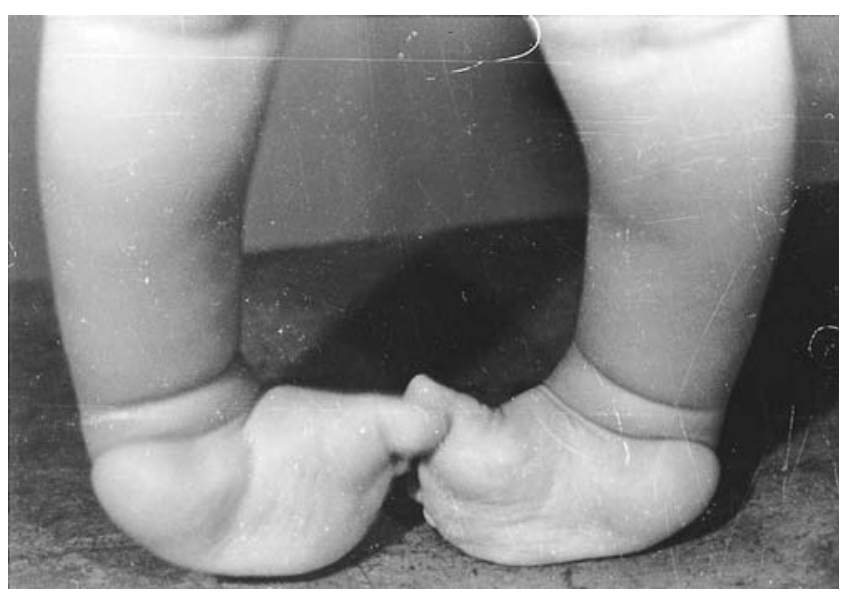

Fig. $2 b$

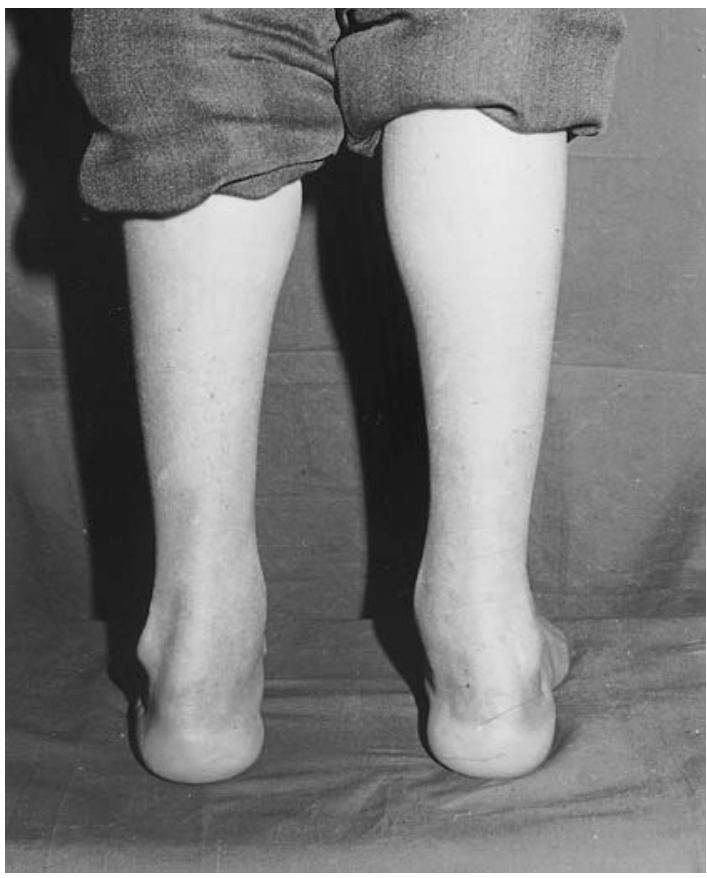

Fig. $2 d$

Pre- $(\mathrm{a}, \mathrm{b})$ and postoperative $(\mathrm{c}, \mathrm{d})$ photographs of a one-year-old boy with bilateral congenital club feet who had percutaneous tenotomy of the tendo Achillis and transfer of the tibialis anterior tendon to the lateral cuneiform. At a follow-up of 12 years the result was rated as excellent.

normal in the 35 feet rated as excellent and good. The dynamic peak pressure under the good and excellent feet was similar, apart from the lower values of peak pressure under the fifth metatarsal head and hallux ( $p<0.05)$, to the control foot. In the seven feet rated fair and poor, the values of static and dynamic peak pressure were lower under the heel and hallux $(\mathrm{p}<0.05)$ and higher under the lateral part of the sole and the head of the fifth metatarsal $(\mathrm{p}<0.05)$. In particular, dynamic peak pressure under the lateral part of the sole and static peak pressure under the hallux were significantly different from the controls $(\mathrm{p}<0.01)$.

Pressure-time integral for the selected areas under the foot. The integrated value of foot pressures relating to time was the same in the feet rated as good and excellent as in the control feet, except for a lower value under the hallux $(\mathrm{p}<0.05)$. In the feet rated as fair and poor, this value was lower under the heel and hallux $(\mathrm{p}<0.05)$, but was higher under the lateral part of the sole and the head of the fifth metatarsal $(p<0.01)$. In particular, the value of the pressure-time integral differed significantly from the control feet under the lateral part of the sole, the head of the fifth metatarsal and the hallux.

\section{Discussion}

Congenital club foot is still an important problem in China as well as in the USA and Western Europe. ${ }^{2-4,7}$ We have developed a grading system, based on the criteria suggested 
by Garceau and Palmer ${ }^{12}$ and others, ${ }^{9,14}$ which relates clinical outcome to appearance, function, muscle strength and balance. Measurements of dynamic and static foot pressures were available for 42 feet.

There have been a number of studies on the muscles of the leg and foot in congenital club foot suggesting the importance of muscle imbalance in the aetiology and management of this condition. ${ }^{10,11,13}$ Treatment by an early operation was aimed at achieving dynamic muscle balance. The foot deformity was first corrected surgically and then the tendon of the tibialis anterior or posterior was transferred laterally to the dorsum of the foot to maintain correction. Satisfactory results were reported in $95 \%$ of the cases after this procedure. ${ }^{4}$ We have obtained good or excellent results in $91.8 \%$ of feet with a similar procedure aimed at correcting the deformity and achieving dynamic muscle balance; 74 feet in 52 patients were skeletally mature at follow-up. In 68 unilateral feet with good or excellent results, there was still significant reduction in the size of the foot and the circumference of the calf.

Tarraf and Carroll ${ }^{18}$ reported residual adduction and supination of the forefoot as the most common persistent deformity in $95 \%$ of 159 club feet which required repeat surgery after primary soft-tissue release. Residual deformity was much less common in our series. Overcorrection was seen if the transfer was too tight or too lateral. We recommend transfer to the lateral cuneiform. The tension in the transfer should maintain the ankle at $0^{\circ}$ to $5^{\circ}$ of dorsiflexion.

Biomechanical assessment was available in 42 feet. In those with good or excellent results the static and dynamic pressures were almost normal, whereas in those with fair or poor results they were significantly different from the controls. This type of measurement can be helpful in assessing results more objectively and in planning further procedures when necessary.

The age of the patient at operation is thought to be an important factor in the long-term outcome. Turco ${ }^{7}$ advised surgery between the ages of one and two years. We feel that it is preferable to operate between the age of six months and one year in order to achieve a balanced corrected foot by the time the child is able to walk. Good or excellent results were obtained in this series in $94 \%$ of patients operated on between the ages of six months and five years. When operation was undertaken at over five years of age this figure fell to $88.2 \%$.

The preoperative severity of the deformity was assessed by the F-M angle. This correlated well with the outcome of surgery. In 29 feet assessed as having mild deformity by this method, $98 \%$ achieved good or excellent results whereas in 60 with severe deformity good or excellent results were achieved in only $88 \%$.

Fair and poor results were associated with incorrect siting and tensioning of the tendon transfer. There were technical problems with slipping of the plaster and break- age of the wire used for suturing the tendon. Two feet showed overcorrection and severe eversion due to transfer of the tendon to the base of the fifth metatarsal. Careful follow-up is advised and if secondary eversion develops it should be corrected by resiting of the tendon in a more medial position.

We advocate surgical treatment of idiopathic congenital club foot by a soft-tissue procedure which corrects the deformity and establishes muscle balance by lateral transfer of the tendon of tibialis anterior to the lateral cuneiform. It is preferable to carry this out between the ages of six months and one year, but satisfactory results can be achieved up to at least five years of age or more.

Part of this work was supported by a grant from China PLA Department of Health. The authors would like to thank $\mathrm{Mr}$ A. Catterall (London, UK) for his critical comment and help in writing this paper and to Mr M. K. D. Benson (Oxford, UK) for his helpful advice to Dr L. Zhao.

No benefits in any form have been received or will be received from a commercial party related directly or indirectly to the subject of this article.

\section{References}

1. Nather A, Bose K. Conservative and surgical treatment of clubfoot. $J$ Pediatr Orthop 1987;7:42-8.

2. Ponseti IV. Treatment of congenital clubfoot. J Bone Joint Surg [Am] 1992;74-A:448-54.

3. Diepstraten AFM. Congenital clubfoot. Acta Orthop Scand 1996;67:305-12.

4. Lu YP, Wang CL, Huang YT, Lu Y, Li MC. Treatment of congenital clubfoot by early operation. Orthopedics 1988;11:1093-101.

5. Yamamoto H, Furuya K. One-stage posteromedial release of congenital clubfoot. J Pediatr Orthop 1988;8:590-5.

6. Esser RD. The medial sagittal approach in the treatment of the congenital clubfoot: a follow-up report of a 15-year experience. Clin Orthop 1994;302:156-63.

7. Turco VJ. Resistant congenital clubfoot: one-stage posteromedial release with internal fixation: a follow-up report of a fifteen year experience. J Bone Joint Surg [Am] 1979;61-A:805-14.

8. Crawford AH, Marxen JL, Osterfeld DL. The Cincinnati incision: a comprehensive approach for surgical procedures of the foot and ankle in childhood. J Bone Joint Surg [Am] 1982;64-A:1355-8.

9. McKay DW. New concept of and approach of clubfoot treatment: section III-evaluation and results. J Pediatr Orthop 1983;3:141-8.

10. Bechtol CO, Mossman HW. Clubfoot: an embryological study of associated muscle abnormalities. J Bone Joint Surg [Am] 1950; 32-A:827-38.

11. Stewart SF. Clubfoot: its incidence, cause and treatment: an anatomical physiological study. J Bone Joint Surg [Am] 1951;33-A:577-90.

12. Garceau GJ, Palmer RM. Transfer of the anterior tibial tendon for recurrent clubfoot: a long-term follow-up. J Bone Joint Surg [Am] 1967;49-A:207-31.

13. Feldbrin Z, Gilai AN, Ezra E, et al. Muscle imbalance in the aetiology of idiopathic club foot: an electromyographic study. $J$ Bone Joint Surg [Br] 1995;77-B:596-601.

14. Laaveg SJ, Ponseti SV. Long-term results of treatment of congenital clubfoot. J Bone Joint Surg [Am] 1980;62-A:23-31.

15. Simons GW. A standardized method for the radiographic evaluation of club feet. Clin Orthop 1978;135:107-18.

16. Duckworth T, Boulton AJM, Betts RP, Franks CI, Ward JD. Plantar pressure measurements and the prevention of ulceration in the diabetic foot. J Bone Joint Surg [Br] 1985;67-B:79-85.

17. Wang J, Liu YP, Huang YT. Establishment and application of a computer video-image processing system for measurement of stress distribution in the sole. Chin J Phys Med 1994;16:27-31.

18. Tarraf YN, Carroll NC. Analysis of the components of residual deformity in clubfeet presenting for reoperation. J Pediatr Orthop $1992 ; 12: 207-16$ 